\title{
COMPARATIVE ANALYSIS OF SMART METERS DEPLOYMENT BUSINESS MODELS ON THE EXAMPLE OF THE RUSSIAN FEDERATION MARKETS
}

\author{
Ildar Daminov ${ }^{1, a}$, Ekaterina Tarasova ${ }^{1}$, Tatyana Andreeva ${ }^{2}$ and Artur Avazov ${ }^{1}$ \\ ${ }^{1}$ National Research Tomsk Polytechnic University, 30 Lenin Av., Tomsk, Russia \\ ${ }^{2}$ National Research Tomsk State University, 40 Lenin Av., Tomsk, Russia
}

\begin{abstract}
This paper presents the comparison of smart meter deployment business models to determine the most suitable option providing smart meters deployment. Authors consider 3 main business model of companies: distribution grid company, energy supplier (energosbyt) and metering company. The goal of the article is to compare the business models of power companies from massive smart metering roll out in power system of Russian Federation.
\end{abstract}

\section{Introduction}

Nowadays, immense work connected with smart metering is underway all over the world. Large-scale projects on massive smart metering system rollout are launched. Italy, France, and the United Kingdom can be shown as an example proving the necessity and efficiency of smart metering deployment. Return on investment takes place in record time for power engineering domain. For instance in Italy primary expenditures were covered for less than 5-year period. Taking into account a huge share of commercial losses in Russian grids, which can reach up to $40 \%$ and even more the payback period for smart metering can take less time [1]. The following study was based on the example of Asino town, Tomsk region, with population of 25000 people. The calculations made by authors have shown that the project of smart metering implementation in the city will pay itself for 3 years. (Fig.1) [2]. The blue line represents the net present value (NPV) of smart metering implementation, the red one is NPV of "as it is" variant or in other words without smart metering.

According to RF Government Regulation from April 15, 2014, № 321 “On approval of the state program of the Russian Federation "Energy efficiency and energy development" the following goal has been established - total share of smart meters must reach $18.9 \%$ by 2020 [3]. The implementation of this technology is the first stage for smart grid, demand response programs, new market player appearance, and also distributed generation integration.

The cornerstone of success for all these programs is defined by the right choice of smart metering deployment business model, which can be performed not only for electricity, but also for gas, heat, and water industry [4-6]. These models will come forward as a study subject. The right model will

\section{${ }^{a}$ Corresponding author: daminovib@gmail.com}


allow effectively consume energy resources, save financial resources and stimulate energy effective events. RF smart metering market has been chosen as the study object.

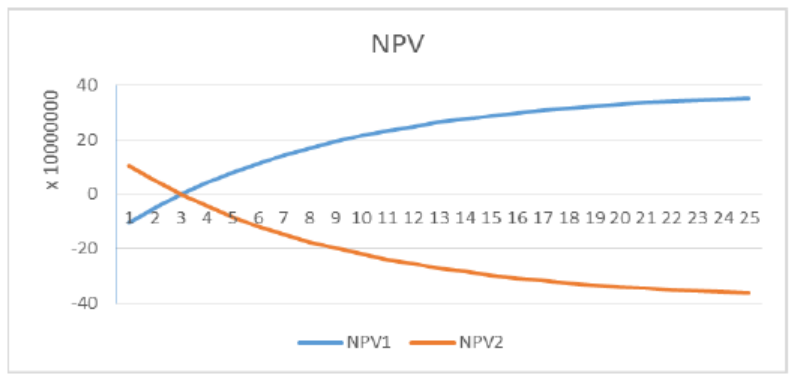

Figure 1. NPV of smart metering project in Asino, Tomsk region.

The goal of this paper is to determine the most efficient smart metering implementation models which will be able to assure the most optimal future development and the next evolution of power engineering industry. This goal attaches the novelty and practical relevance of this paper since such study has not been performed in Russia yet. The tasks are consideration and comparison of models: DGC, Energosbyt, and Metering company.

\section{Market models}

Smart meter deployment can be performed by 3 different ways, in other words, using 3 different market models (Fig.2).

1. Distribution grid company (DGC) is an owner of smart meter and it performs the metering infrastructure control and it provides metering services. Such model is best matched to the current market structure of Russia and meets the least industry resistance during smart meter installation. The smart meter deployment can be performed with fewer resources and work processes. However, there are risks of equipment and data transfer protocols compatibility in future since every Russian DGC uses the equipment of various manufacturers thereby isolated systems appear operating with different functional capabilities. Such problem can become pressing when Russia will need to get the equal system capabilities of smart metering for demand response program. It is also possible a creation of doubling communication networks for gas, heat and water industries that will lead to an increase of investment cost.

2. A metering company (MC) - is a brand new market player established to meet the metering services needs. Smart meters are on the balance of the Metering Company. One Metering company can provide its services for the whole range of utilities: electricity, water, gas and heat supply. Thus, the synergetic effect is reached through the lowering of investment costs for utilities. A metering company is able to cover the country with only one zone. Either DGC or a metering company can be responsible for meters operation and ownership. The example of such a company is the UK DCC.

3. Energy supplier (Energosbyt) performs the metering function on liberalized market using existing agreement relations with the customer. Smart meters are on the balance of energy supplier company. In this case, a smart meter will not be perceived as part of the distribution grid.

These theoretical models are base ones. In real application, there is a plurality of their variations. 

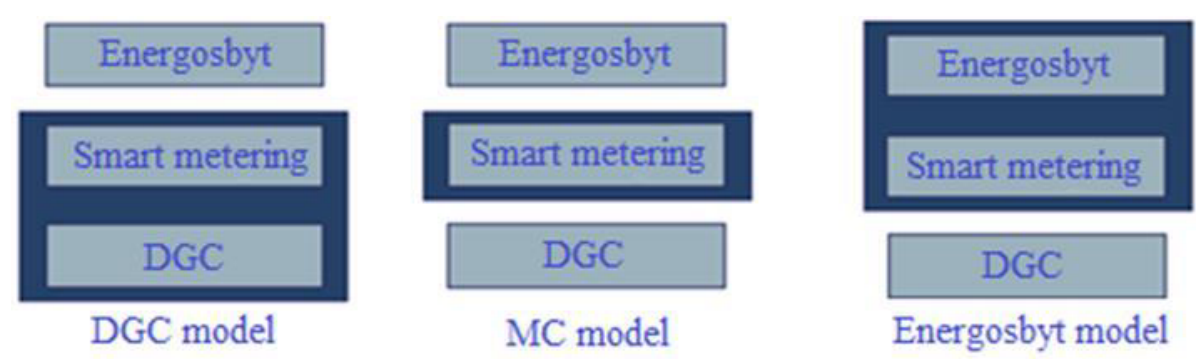

Figure 2. Different market models [7].

\section{Comparative analysis of models}

A comparison of the models will be carried out according to the criteria given in the Assessment of smart metering models: the case of Hungary [8].

1. The cost of smart metering deployment

- DGC model. Distribution companies can use the existing infrastructure of its own - low-voltage lines for the data transmission from smart meters using PLC technology. Thus, DGC can lower capital and operating costs of the smart metering implementation. However, in the case of other utilities gas, heat and water - it can be sufficiently difficult to determine the transfer technology.

- Energosbyt Model. As there is a need of new infrastructure it is expected that the level of spending is the highest in comparison with other models since the Energy Supply Company does not own the low-voltage transmission lines as it is in the case of DGC.

- MC Model. Since the structure of company ownership may be different, this can stipulate the reduction of the implementation costs. That is the case when smart meters belong to the DGC on a contractor basis and it also transmits data from smart meters to the concentrator.

2. Time of implementation

- For DGC and Energosbyt models, there are no significant differences in the deployment of smart meters. However, the DGC model will allow deployment in the shortest possible time.

- MC model involves more time due to the fact that a new company is established as well as contracts and other forms of relation should be set with other actors i.e. DGC and Energosbyt, which also increases the time for connection to the grid.

3. The impact on competition in the industry

- DGC model. Currently, there is no competition among the DGCs in Russia. The success of the model depends on the level of deregulation.

- Energosbyt Model supports competition among energy supply companies. However, the energy suppliers' market concentration is the indicator of low competition in the retail market. According to the analytical report "Analysis of the power industry reform and proposals to increase its effectiveness" made by the Institute of Natural Monopolies the situation in the retail electricity market remained virtually unchanged if compared to the period before deregulation. All energy suppliers are still confined to geographical boundaries of their subjects of the Russian Federation. They do not operate by groups of supply points, i.e. in fact, in most regions there is no guaranteed alternative supplier. In 2011, the share of each energy supplier reached almost 75\%. In most regions, this figure is close to $100 \%$ [9]. Moreover, if the energy supplier is changed then what institution will have the smart meters on balance? All these issues add uncertainty to the case.

- MC Model supports competition at the highest level since the MC does not have its own interests in the industry. One variation of this model is the variety of metering companies which are competing with each other.

4. Barriers to entry for new technologies

- DGC model generally supports them. However, the advantage is highly probable to be given to its PLC technology. 
- Energosbyt model, as well as DGC, will support them too. However, it does not have an explicit interest in bringing new technologies in addition to the PLC.

- MC Model is most open to new technologies. It is not dependent on a certain data transmission method.

5. Energy efficiency enhancement

- DGC Model. In the short term, DGC may be interested in supplying the largest possible amount of electricity, partially because of its consumption-related tariff.

- Energosbyt Model. The company is interested in supplying the largest possible amount of power for the sake of profit.

- MC Model has no conflicts of interest to reduce consumption and consequently it can effectively support energy efficiency enhancement programs.

\section{Model selection}

This section provides a selection of business model:

- Basing on the previous assessment the Energy Supply Company model is considered to be as less suitable for implementation. No country uses the model of the energy supply company in this form.

- DGC Model and independent metering company model are thought to be more suitable for the application. The choice between them will depend on the goals and preferences when deployment of smart meters is underway.

- Market competition is mostly supported by DGC and MC models due to the fact that the change of power Supply Company will be more complicated.

- DGC model is mostly consistent with the existing operating scheme in the industry

-Independent metering company model corresponds to the targets of energy saving to a greater extent.

\section{Conclusion}

This study provided a comparison of the business models by a wide range of parameters. Having analyzed the results it was decided that the Model of the energy supply company is considered to be less suitable for use due to the direct contradiction in profit - energy efficiency ratio. This model is never used in a pure form. DGC and independent metering company models were selected as more suitable for the application. The choice between them will be conditioned by the goals and preferences during deployment of smart meters.

Market competition is mainly supported by DGC and MC models as the procedure of energy supplier change will be complicated under existing circumstances. DGC model is highly consistent with the current scheme operating in the industry.

The model of the independent metering company fully meets the energy efficiency targets. In reality, these models are unlikely to be used in its pure representation i.e. a lot of hybrid options are more likely to appear.

Currently, Russia uses DGC model. However, there was no work on the preliminary cost-benefit analysis (CBA analysis), which would have justified the optimal choice of this model. Therefore, the smart meters roll-out process has the more chaotic pattern and does not consider future development of the industry.

The authors would recommend implementing CBA analysis for the full-scale smart meter roll-out, thus taking into account other areas where smart meters can be used: e.g. gas, water and heating. In the latter case, the smart metering will lead to the justification and validation of the metering company model. 


\section{References}

1. Poteryat' nel'zya ekonomit'- URL: http://www.kommersant.ru/doc/2189201

2. I. Daminov, Smart metering project in Asino, Russia. Master thesis (Grenoble, 2015)

3. Government Decree of April 15, 2014 N 321 "On approval of the state program of the Russian Federation" Energy and Energy Development" " URL: http://minenergo.gov.ru/upload/iblock/b6b/b6b29df2dcbb578dc1073b4fb18f9412.pdf

4. M. Cotti, F. Veroni, P. Giubbini Advanced smart multi-metering: Synergies between gas and electricity sectors for efficient operations and customer awareness, 22nd International Conference and Exhibition on Electricity Distribution,43, 1146 (2015)

5. P. Harris, P. Guttmann, Smart water metering in the Victorian urban water sector, 37, 44 (2010)

6. T.Fang, R. Lahdelma, Genetic optimization of multi-plant heat production in district heating networks, 159, 610 (2015)

7. D. Balmert, D. Grote, K. Petrov, Development of Best Practice Recommendations for Smart Meters Rollout in the Energy Community. Final report (Athens, 2012)

8. Assessment of Smart metering models: The Case of Hungary. Final Report (Hungary, 2010)

9. Analysis of the power industry reform and proposals to increase its effectiveness - URL: http://www.ipem.ru/files/files/research/27_05_2013_power_reform_analysis.pdf 